\title{
Chronic Trypanosoma cruzi-elicited cardiomyopathy: from the discovery to the proposal of rational therapeutic interventions targeting cell adhesion molecules and chemokine receptors - how to make a dream come true
}

\author{
Joseli Lannes-Vieira' ${ }^{1,2}{ }^{+}$, Jaline Coutinho Silverio ${ }^{2}$, Isabela Resende Pereira ${ }^{2}$, Nathália Ferreira Vinagre ${ }^{2}$, \\ Cristiano Marcelo Espinola Carvalhoº ${ }^{2}$, Cláudia Neto Paiva ${ }^{3}$, Andréa Alice da Silva ${ }^{4}$ \\ 1Programa Integrado de Doença de Chagas-Fiocruz (PIDC) 2'Laboratório de Biologia das Interações, Instituto Oswaldo Cruz-Fiocruz, \\ Av. Brasil 4365, 21045-900 Rio de Janeiro, RJ, Brasil '²Departamento de Imunologia, Instituto de Microbiologia Prof. Paulo de Góes, Universi- \\ dade Federal do Rio de Janeiro, Rio de Janeiro, RJ, Brasil ${ }^{4}$ Departamento de Patologia, Universidade Federal Fluminense, Niterói, RJ, Brasil
}

One hundred years ago, Carlos Chagas discovered a new disease, the American trypanosomiasis. Chagas and co-workers later characterised the disease's common manifestation, chronic cardiomyopathy, and suggested that parasitic persistence coupled with inflammation was the key underlying pathogenic mechanism. Better comprehension of the molecular mechanisms leading to clinical heart afflictions is a prerequisite to developing new therapies that ameliorate inflammation and improve heart function without hampering parasite control. Here, we review recent data showing that distinct cell adhesion molecules, chemokines and chemokine receptors participate in anti-parasite immunity and/or detrimental leukocyte trafficking to the heart. Moreover, we offer evidence that CCchemokine receptors may be attractive therapeutic targets aiming to regain homeostatic balance in parasite/host interaction thereby improving prognosis, supporting that it is becoming a non-phantasious proposal.

Key words: Chagas disease - Trypanosoma cruzi - cardiomyopathy - chemokine - chemokine receptors - cell adhesion molecules

In 1909, Carlos Chagas realised a unique medical finding describing a new disease known as American trypanosomiasis, as well as its vector and causative agent, the haemoflagellate protozoan Trypanosoma cruzi (Chagas 1909). This discovery initiated a movement to characterise the disease's clinical manifestations and epidemiological significance (Laranja et al. 1956). One hundred years after its discovery, Chagas disease is still epidemiologically relevant, afflicting 12-14 million people in 18 endemic countries in Latin America (Coura 2007, Dias 2007). Several hundred thousand T. cruzi-infected individuals may also be living in North America, Europe and other countries as a result of immigration to these areas in search of a better life (Schmunis 2007), demonstrating that Chagas disease is a far-reaching public health issue.

Chagas' (1909, 1911) initial studies described the peculiar clinical symptoms associated with American trypanosomiasis, including cardiac excitability disturbance, extrasystoles, abnormal conduction and complete

Financial support: CNPq (301504/2005-9, 302534/2008-3), FAPERJ (E-26/111.756/2008), DECIT/MS/CNPq/MCT, The Millennium Institute for Vaccine Development and Technology (420067/2005-1), INCT/CNPq (fellowships from CNPq: JLV, IRP, JCS)

+ Corresponding author: lannes@ioc.fiocruz.br

Received 20 April 2009

Accepted 1 June 2009 heart blockage. In 1916, Chagas compiled the histopathological findings from acute and chronic cases of human as well as experimental T. cruzi infection. Based on these data, he proposed that the pathogenic mechanism underlying cardiac symptoms was intense parasitism coupled with inflammation during the acute phase and parasite persistence, "although in small numbers inside cardiomyocytes making them difficult to find", in parallel with inflammation during chronic infection (Fig. 1). Curiously, Chagas described the presence of amastigote forms of the parasite in the heart tissue of chronically infected individuals (Fig. 1). Assuming that inflammation was not proportional to the small numbers of parasite nests, he claimed that the inflammatory lesions resembled "an allergic process". However, Chagas noted that in "most of the chronic cases with predominant cardiac signs a large number of protozoa is observed in the myocardium and the inflammatory reactions of the organ is also more intense" (Chagas 1916).

During the following years, Chagas and Villela (1922) adopting a new non-invasive procedure for recording the heart's electrical activity (electrocardiography, or ECG) and recently described parameters to characterize heart abnormalities defined the precise cardiologic profiles of acutely and chronically $T$. cruzi-infected patients. However, three decades passed before for Chagas' original observations of cardiac disturbances during chronic $T$. cruzi infection were reproduced in experimentally infected dogs (Laranja et al. 1950, 1956) and confirmed in a large number of patients (Laranja et al. 1956). Chagas' detection of parasite nesting in cardiomyocyte or phagocytized by macrophages in all studied chronic chagasic 

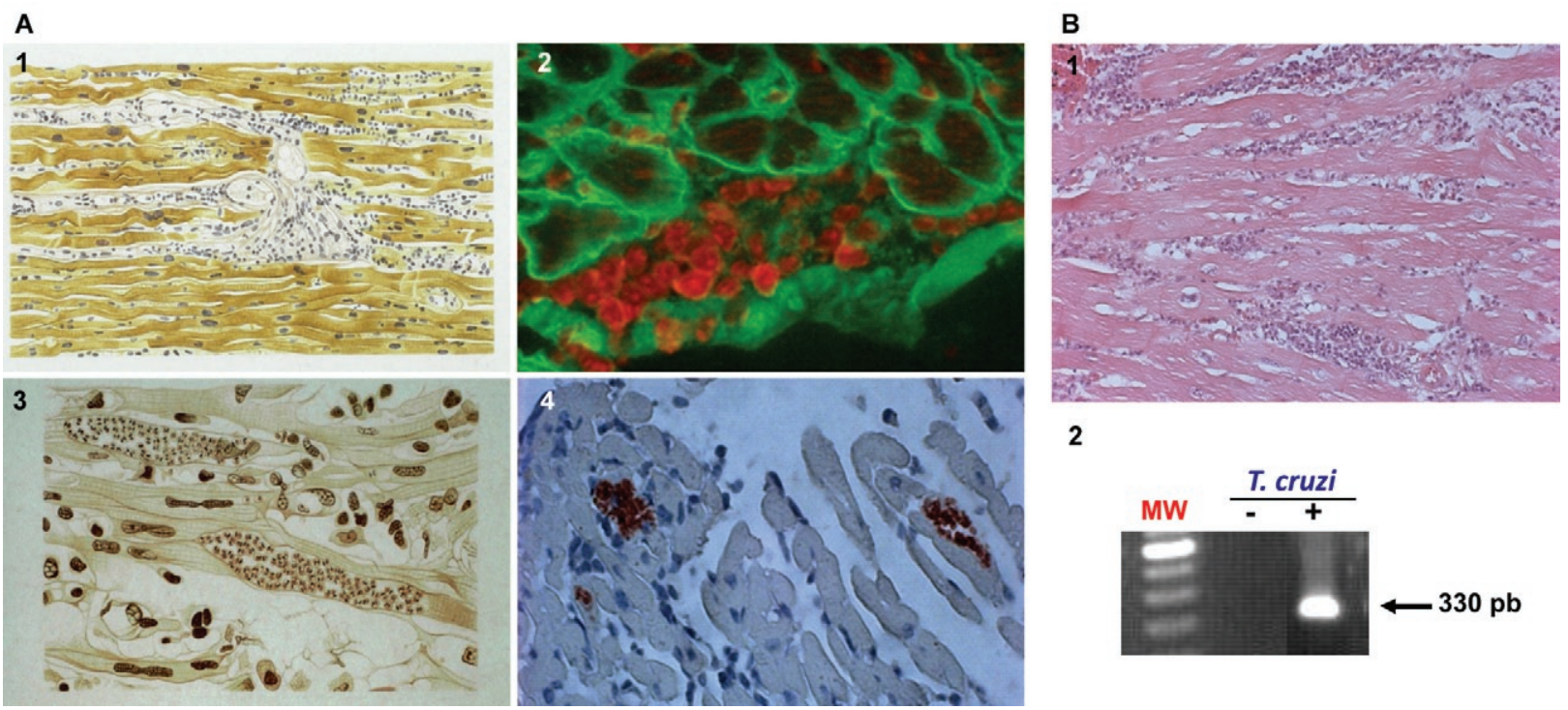

2

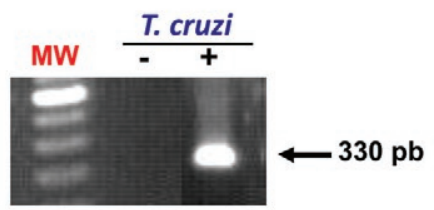

Fig. 1: histophatological alterations observed in the heart tissue of Colombian strain infected $\mathrm{C} 3 \mathrm{H} / \mathrm{He}$ mice reproduce the original findings described by Chagas (1916) in patients. A: in 1916, Chagas showed the presence of an intense inflammatory infiltrate in the heart of patients acutely infected by $T$. cruzi (1). The presence of inflammatory cells in the heart tissue of acutely Colombian-infected mice (2) is shown using confocal microscopy (1,000X) (Roffê et al. (2003) (red: inflammatory cell; green: cardiomyocytes). Similarly to Chagas's description showing the presence of amastigote forms of the parasite in the heart tissue of chronically infected individuals (3), we detected the presence of $T$. cruzi antigens (4) (400X), immunohistochemistry carried out (dos Santos et al. 2001); B: in the case of apparent absence of the parasite in inflammatory chronic heart lesions (1) (200X, H\&E staining), parasite DNA was detected during the chronic phase of experimental infection (2). PCR conditions described in Carvalho et al. (2003). Authorized reproduction of drawings published in Chagas (1916).

cardiomyopathy (CCC) patients (Chagas 1916, Chagas \& Vilella 1922), although "a time-consuming activity" was also confirmed by Laranja et al. (1956). Moreover, cardiac histopathological abnormalities were characterised as consisting of diffuse and focal heart inflammatory foci chiefly composed of lymphocytes, plasma cells and macrophages, as well as eosinophils and neutrophils. Focal and diffuse fibrosis of the myocardium was also evidenced in all cases, its intensity varying from case to case and from one area to another within the same case (Laranja et al. 1956). Together, these findings provide a firm basis for defining $\mathrm{CCC}$ as a distinct clinical and anatomical entity.

Intriguingly, T. cruzi parasites were not observed in the cardiac tissue lesions of most patients with chronic Chagas disease for decades. Scientists began to ascribe a major role to autoimmune reactions in CCC pathogenesis (Santos-Buch \& Teixeira 1974, Ribeiro dos Santos \& Hudson 1980, Kierszenbaum 1985), a theory that hampered efforts to develop chemotherapy and vaccine against $T$. cruzi (Kierszenbaum 2005). The importance of parasite persistence in CCC pathogenesis was finally reaffirmed nearly 80 years after Chagas' pioneering work (Chagas 1916) using immunohistochemistry and molecular biology to analyse the heart tissue of CCC patients (D’Avila Reis et al. 1993, Higuchi et al. 1993, Jones et al. 1993, Reis et al. 1997), as well as ingenious cell transfer studies in experimental models (Tarleton et al. 1997). Currently, it is widely believed that chagasic cardiac injury results from an imbalanced effector immune response elicited by parasite persistence (Higuchi et al. 2003, Kierszenbaum 2005).

Adopting the experimental model consisting of female $\mathrm{C} 3 \mathrm{H} / \mathrm{He}$ mice infected with low-dose inocula of the Colombian T. cruzi strain, we demonstrated the presence of parasite nests and the persistence of parasite DNA in inflammatory cardiac lesions (Fig. 1), reproducing earlier findings in chronic chagasic patients (Higuchi et al. 1993, Jones et al. 1993). Our model also replicates Chagas' main findings in CCC patients (Chagas 1916, Chagas \& Vilella 1922), including (i) parasitaemia control and acute phase survival; (ii) chronic increase in relative heart weight; (iii) acute and chronic myocarditis; (iv) cardiomyocyte lesions and (v) electrical abnormalities (Fig. 2).

In the past several years, many groups have sought to elucidate the physiopathogenesis of CCC and cardiomyopathy (Higuchi et al. 2003, Marin-Neto et al. 2008). Nevertheless, new therapeutic approaches, beyond already available anti-parasite drugs and interventions targeting symptoms, have not been developed (Marin-Neto et al. 2008, Soeiro \& de Castro 2009). Since cardiac transplant is currently the only effective treatment for Chagas disease-induced heart failure, cell-based therapy aiming to recover heart function is a desirable alternative, although expensive and still restricted to clinical trials (Soares \& Ribeiro dos Santos 2009). The major challenge in designing efficacious treatment for T. cru$z i$-elicited cardiomyopathy is to reduce inflammation, 
A

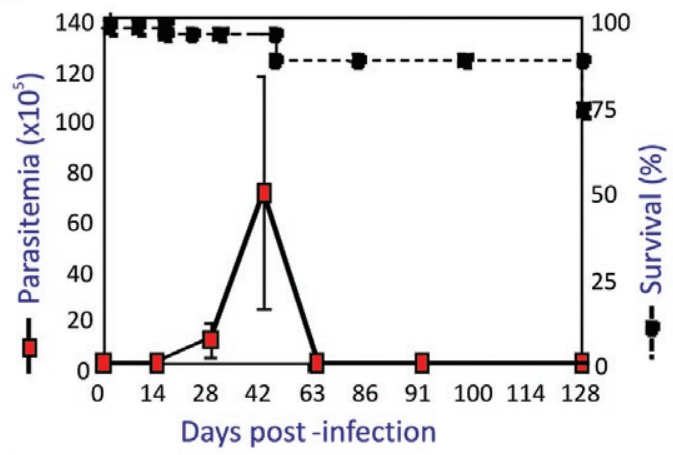

C

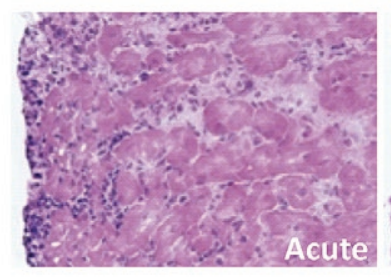

B

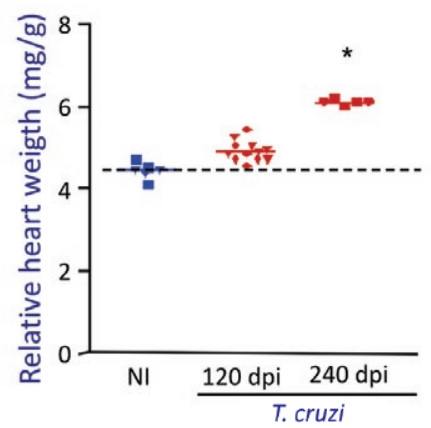

D

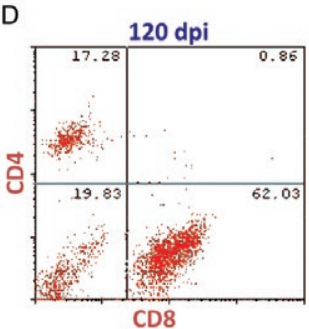

E

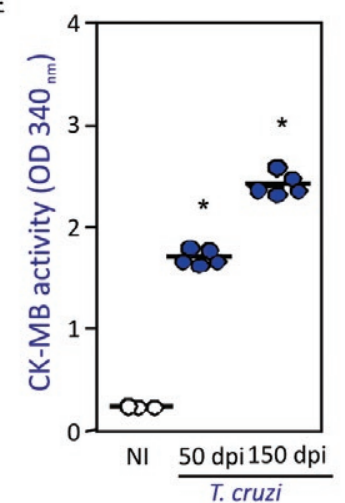

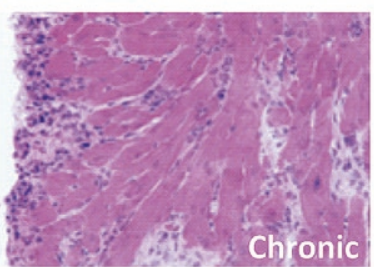

F

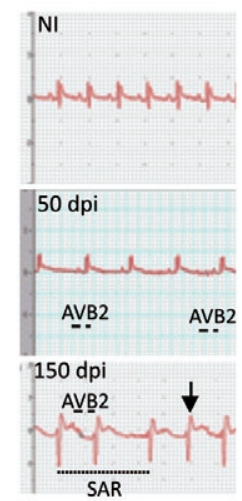

Fig. 2: experimental model reproduces different findings of the cardiac form of Chagas disease. Five to seven-week-old female $\mathrm{C} 3 \mathrm{H} / \mathrm{He}(\mathrm{H}-$ $2^{\mathrm{k}}$ ) mice were infected with 100 trypomastigote forms of the Colombian Trypanosoma cruzi strain (dos Santos et al. 2001). Panel A shows parasitemia (red squares) and survival curves (black squares). Increase in relative heart weight is observed at 120 days post-infection (dpi) and mainly, at $240 \mathrm{dpi}$ (red triangles and squares, respectively) compared to non-infected $\mathrm{C} 3 \mathrm{H} / \mathrm{He}$ mice (blue squares/triangles). In panel C, histopathological analysis $(400 \mathrm{X}, \mathrm{H} \& \mathrm{E})$ shows acute $(50 \mathrm{dpi})$ and chronic (120 dpi) mononuclear cell inflammation in the cardiac tissue of infected mice. Flow cytometry analysis of the mononuclear cells isolated from cardiac tissue of chronically (120 dpi) $T$. cruzi-infected mice (dos Santos et al. 2001) shows the predominance of $\mathrm{CD}^{+} \mathrm{T}$ cells over $\mathrm{CD} 4^{+} \mathrm{T}$ cells (D). Cardiomyocyte damage was evaluated by CK-MB activity in sera of acute (50 dpi) and chronically (150 dpi) infected (blue circles) in comparison with non-infected (white circles) C3H/He mice (E) (Kroll-Palhares et al. 2008). ECG recordings from non-infected and T. cruzi-infected mice (F) [ECG recorded as shown in Silverio et al. (2009), unpublished observations]. The lines indicate: -, second-degree atrioventricular block; ---: sinusal arrhythmia. The arrow ( $\downarrow$ ) represents supra unlevelling. Mean \pm SD values for 5-10 mice are shown and data are representative of three independent experiments. ${ }^{*}: \mathrm{p}<0.05 ; * *: \mathrm{p}<0.01$.

which causes severe tissue damage, without hampering immunological control of parasitism. A more thorough understanding of CCC pathogenesis and its underlying molecular mechanisms may thus help to delineate new therapeutic strategies.

Here, we critically review our and other recent data exploring the participation of cell adhesion molecules (CAM) and CC-chemokines and their receptors in the multi-step process of cell migration during T. cruzielicited myocarditis and CCC formation. We also offer evidence that these molecular pathways are rational therapeutic targets for modulating detrimental cardiac inflammation during chagasic infection without hampering parasite control.

\section{Key players in leukocyte migration to injured tissues}

The three crucial steps of leukocyte migration to injured non-lymphoid tissues (rolling, adhesion and transmigration) were first described in the XIX century (Ley et al. 2007). However, only in the last decade of the XX century, after the discovery of molecules involved in the leukocyte migration cascade, has this multi-step 
model emerged as a concept and begun to unravel the leukocyte recruitment process to injured tissue (Butcher 1991, Springer 1995). In the original model, Butcher and Springer proposed three steps underlying leukocyte migration: (i) selectin-mediated rolling; (ii) chemokinedriven activation and (iii) integrin-dependent arrest or firm adhesion. However, recent findings have revealed that the leukocyte migration cascade is more complex, involving tethering or capture, rolling, arrest or firm adhesion, recruitment, transendothelial migration (intraluminal crawling and paracellular and transcellular migration), extravasation through the basement membrane and positioning (Ley et al. 2007, Sigmundsdottir \& Butcher 2008). Notably, all of these studies confirmed the participation of chemokines, chemokine receptors and CAM in leukocyte trafficking to injured tissues.

Chemokines are small (8-14 kDa) chemoattractant cytokines that are either constitutively expressed or induced in response to inflammation. These proteins comprise four subfamilies (CXC or $\alpha, \mathrm{CC}$ or $\beta, \mathrm{C}$ or $\gamma$ and $\mathrm{CX}_{3} \mathrm{C}$ or $\delta$ ) that act on G-protein-coupled serpentine receptors on target cells. Generally, CXC-chemokines act on neutrophils and on $\mathrm{T}$ and $\mathrm{B}$ cells, while $\mathrm{CC}$ chemokines affect a wider spectrum of cell populations, including monocytes, basophils, eosinophils, T cells, dendritic cells and natural killer cells, but do not act on neutrophils. It is likely that all cell types, such as endothelial cells, cardiomyocytes, fibroblasts, $T$ cells and macrophages, produce a variety of chemokines when adequately stimulated (Bromley et al. 2008, Viola \& Luster 2008). Chemokines act in a context-dependent manner, varying in function according to whether they are in soluble or extracellular matrix-anchored form (Sigmoundsdottir \& Butcher 2008). Their biological functions are numerous, including facilitating (i) cell adhesion to the endothelium and extracellular matrix components; (ii) leukocyte chemotactic migration: (iii) angiogenesis control; (iv) extracellular matrix production control; (v) regulation of T-lymphocyte growth, activation and differentiation (including Th1/Th2 commitment); (vi) release of intracellular reserve of enzymes; (vii) oxygen radical formation; (viii) cytoskeleton alteration; (ix) generation of lipid mediators of intracellular activation signals; (x) haematopoietic precursor proliferation and (xi) control of pathogen invasion and propagation. Chemokines may thus play an important role in the regulation of host resistance to pathogens and in the immunopathogenesis of various conditions, including autoimmune and infectious diseases (Proudfoot 2002, Bromley et al. 2008, Viola \& Luster 2008).

CAM, which are mainly members of the selectin, integrin and immunoglobulin superfamilies, participate in all cell migration steps involving cell-cell and cell-extracellular matrix interactions (Luo et al. 2007). These molecules are widespread, present on a variety of cell types and involved in diverse biological events, including (i) ontogenesis; (ii) immunological synapse formation; (iii) cell activation; (iv) immunological surveillance; (v) cell extravasation to injured tissue; (vi) cell positioning and (vii) cell-pathogen interactions (Luo et al. 2007, Abram \& Lowell 2009). Importantly, chemokine-triggered mod- ulation of integrin affinity is a crucial step in cell arrest or firm adhesion to the activated endothelium, making this process a potential target for impairing cell extravasation during chronic inflammatory diseases (Kummer \& Ginsberg 2006, Ley et al. 2007, Luo et al. 2007, Viola \& Luster 2008).

\section{T. cruzi-elicited myocarditis}

Although an inflammatory response seems to be required for parasite control in acute Chagas disease, about $30-40 \%$ of patients also develop chronic myocarditis with prominent fibrosis and organ dysfunction (Higuchi et al. 2003, Marin-Neto et al. 2008). During the chronic phase, inflammatory heart infiltrates, which are not directly related to the rare parasite presence, are mainly composed of mononuclear cells, lymphocytes and macrophages, although neutrophils and eosinophils are also occasionally detected (Chagas 1916, Laranja et al. 1956, Reis et al. 1993, Higuchi et al. 1997, dos Santos et al. 2001). Among the lymphocytes, $\mathrm{CD} 8^{+} \mathrm{T}$ cells outweigh $\mathrm{CD}^{+} \mathrm{T}$ cells in the focal and diffuse heart infiltrates of CCC patients (Reis et al. 1993, Higuchi et al. 1997) and chronically infected experimental models (dos Santos et al. 2001, Medeiros et al. 2009). Conversely, there is a direct relationship between parasite presence and $\mathrm{CD} 8^{+} \mathrm{T}$ cell prevalence during cardiac inflammation (Higuchi et al. 1997). However, the molecular forces governing $\mathrm{CD}^{+}$ $\mathrm{T}$ cell-enriched myocarditis, as well as the chemokines and CAM influencing cell migration and positioning in the cardiac tissue, are not yet well defined. The functional role of invasive inflammatory cells in parasite control and cardiomyopathy is also still unknown.

\section{Participation of CAM in T. cruzi-induced myocarditis and cardiomyopathy}

Initial studies of CAM participation in Chagas disease revealed high serum levels of soluble vascular CAM-1 (sVCAM-1 or CD106), intercellular adhesion molecule-1 (ICAM-1 or CD54) and CD44 (ligand of fibronectin and hyaluronic acid) during the acute phase of infection, whereas soluble P-selectin (sP-selectin or CD62P) was associated with chronic disease severity (Laucella et al. 1996a). Furthermore, sP-selectin and sVCAM-1 levels were found to be elevated in children with indeterminate Chagas disease, but decreased after benznidazole treatment, as compared with children receiving a placebo (Laucella et al. 1999). CAM release is triggered by the same stimuli that increase their cell surface expression, such as interferon- $\gamma$ (IFN- $\gamma$ ) and tumour necrosis factor (TNF). In this context, CCC is associated with (i) increased expression of both ICAM-1 and VCAM-1 on the cardiac vascular endothelium; (ii) increased numbers of cardiac tissue-invading lymphocytes expressing leukocyte function-associated antigen-1 (LFA-1 or CD11a/ CD18; ligand of ICAM-1), very late antigen-4 (VLA-4 or CD49d/CD29, $\alpha 4 \beta 1$; ligand of VCAM-1) and CD44 and (iii) upregulation of class I major histocompatibility complex on cardiomyocytes (Benvenuti et al. 2000) in the presence of parasite antigens and $\mathrm{CD}^{+} \mathrm{T}$ cell-enriched inflammation (D'Avila Reis et al. 1993, Higuchi et al. 1993, Reis et al. 1997). Based on these in situ find- 
ings, it is reasonable to propose that CAM contribute to chagasic myocarditis formation by mediating lymphocyte adhesion to the cytokine-activated endothelium of cardiac blood vessels. Moreover, one could speculate that LFA- $1^{+}$lymphocytes may adhere to ICAM-1-bearing cardiomyocytes, contributing to parasite control but also causing tissue lesions (Benvenuti et al. 2000). CAM may thus play an integral role in creating an appropriate scenario for chagasic heart failure, a role that is currently being elucidated experimentally.

Adopting $\mathrm{C} 3 \mathrm{H} / \mathrm{He}$ mice infected with the Colombian $T$. cruzi strain, which develop $\mathrm{CD} 8^{+} \mathrm{T}$ cell-enriched cardiomyopathy and increased heart relative weight, cardiomyocyte lesions and ECG abnormalities (Fig. 2), we demonstrated that both $\mathrm{CD}^{+}$and $\mathrm{CD} 8^{+} \mathrm{T}$ cells infiltrating the heart tissue exhibit the activation phenotype CD62L-/low, LFA- $1^{\text {high }}$ and VLA- $4^{\text {high }}$. In addition, a higher proportion of circulating $\mathrm{CD} 8^{+} \mathrm{T}$ cells than $\mathrm{CD} 4^{+}$ $\mathrm{T}$ cells are LFA- $1^{\text {high }}$ and VLA-4 $4^{\text {high }}$, which may allow interaction of these circulating cells with ICAM $-1^{+}$and VCAM- $1^{+}$activated endothelium (dos Santos et al. 2001). This potential interaction could facilitate the preferential migration to and predominance of these $\mathrm{T}$ cells in the myocardium of chronically $T$. cruzi-infected animals. Interestingly, in $T$. cruzi-infected $\mathrm{C} 3 \mathrm{H} / \mathrm{He}$ mice, the increased frequency of LFA- $1^{+}$and VLA- $4^{+}$circulating T cells and the upregulation of ICAM-1 and VCAM-1 on the cardiac vascular endothelium coincide with inflammatory cell invasion of this tissue (Marino et al. 2003). Using interleukin-12 (IL-12)-and IFN- $\gamma$-deficient mice, we have also found that IFN- $\gamma$ modulates ICAM- 1 expression on endothelial cells and on the sarcolemma of cardiomyocytes (Michailowsky et al. 2004). However, a study implementing IFN- $\gamma$ receptor-deficient mice claimed that cardiac ICAM-1 expression in T. cruzi-infected mice is IFN- $\gamma$-independent (Laucella et al. 1996b), suggesting that other inflammatory factors or parasite products per si may also contribute to CAM upregulation during T. cruzi infection. In fact, in vitro T. cruzi infection of endothelial cells induces VCAM-1 and Eselectin and upregulates ICAM-1 via nuclear factor- $\kappa \mathrm{B}$ (NF-KB) activation (Huang et al. 1999).

Infection of ICAM-1 ${ }^{-/}$mice indicated a role for ICAM-1 in T. cruzi-elicited myocarditis formation. The high susceptibility of ICAM-1-deficient animals to T. cruzi infection was associated with a decreased number of $\mathrm{CD}^{+}$and $\mathrm{CD} 8^{+} \mathrm{T}$ cells invading the cardiac tissue, implying that LFA-1/ICAM-1-mediated cell migration to the heart is essential for myocarditis formation and thus for protective anti-T. cruzi responses (Michailowsky et al. 2004). However, whether different CAM have distinct roles in protective immunity and in the induction of chronic inflammation in Chagas disease is still unclear. A better understanding of the role of CAM in T. cruzielicited myocarditis and $\mathrm{CCC}$ may pave the way to facilitate targeting of these molecules to treat Chagas disease. CAM antagonists have already been implemented in the treatment of chronic inflammatory diseases, including rheumatoid arthritis, multiple sclerosis and Crohn's disease (Kummer \& Ginsberg 2006, Abram \& Lowell 2009), indicating the feasibility of this therapeutic approach.

\section{Chemokines and chemokine receptors in $T$. cruzi- elicited myocarditis and cardiomyopathy}

During T. cruzi infection, cytokines, chemokines and other immune mediators are generated in the affected heart tissue, triggering intense leukocyte migration (Talvani et al. 2000, dos Santos et al. 2001, Marino et al. 2004, Medeiros et al. 2009). CC- or $\beta$-chemokines appear to be particularly beneficial to the host during $T$. cruzi infection. The parasite or its molecules have been found to induce human and murine macrophages as well as murine cardiomyocytes to produce CC-chemokines in vitro (Lima et al. 1997, Villalta et al. 1998, Aliberti et al. 1999, Machado et al. 2000, Talvani et al. 2000). Addition of macrophage inflammatory protein-1 $\alpha$ (MIP-1 $\alpha$, or CCL3), MIP-1 $\beta$ (or CCL4) or RANTES (Regulation on Activation, Normal T-cell Expressed and Secreted or CCL5) to such infected macrophages and cardiomyocytes resulted in increased parasite up-take and destruction by a nitric oxide-dependent mechanism (Aliberti et al. 1999, Machado et al. 2000). This finding suggests that parasites regulate chemokine production, which keeps the parasite under control and thus prevents host death.

Treatment of $T$. cruzi-infected cardiomyocytes with TNF also leads to induction or augmentation of CCchemokine expression (Machado et al. 2000). Interestingly, TNF- or IFN- $\gamma$-treated T. cruzi-infected macrophages express more $\mathrm{CC}$-chemokines than untreated cells, while IL-10 and transforming growth factor- $\beta$ (TGF- $\beta$ ) reduce $\mathrm{CC}$-chemokine production, suggesting that pro-inflammatory and regulatory cytokines control parasitism and myocarditis via chemokine-dependent mechanisms (Aliberti et al. 1999). Additionally, the CC-chemokine monocyte chemoattractant protein-1 (MCP-1 or CCL2) directly triggers the chemotaxis and morphogenesis of the trypomastigote forms of $T$. cruzi (Yamauchi et al. 2006), implicating CC-chemokines as crucial actors in directing parasite to certain tissues and contributing to explain T. cruzi tissue tropism (Melo \& Brener 1978).

Elevated mRNA levels of several chemokines [CCL2/ MCP-1, CCL3/MIP1 $\alpha$, CCL4/MIP-1 $\beta$, CCL5/RANTES, monokine induced by IFN- $\gamma$ (MIG or CXCL9), interferon-inducible protein-10 (IP-10 or CXCL10) and RANTES] have been observed in the cardiac tissue, associated with the formation of inflammatory infiltrates of various murine models of acute and chronic $T$. cruzi infection (Talvani et al. 2000, Aliberti et al. 2001, dos Santos et al. 2001, Marino et al. 2004). Indeed, we recently demonstrated that myocarditis intensity during both the acute and the chronic phases of infection in $\mathrm{C} 3 \mathrm{H} / \mathrm{He}$ mice is directly correlated with the CC-chemokines CCL3/MIP$1 \alpha$ and CCL5/RANTES but not the cytokines IFN- $\gamma$ and TNF, concentrations in the cardiac milieu (Medeiros et al. 2009), reaffirming CC-chemokine participation in $T$. cruzi-elicited myocarditis formation and perpetuation.

Treatment of Colombian T. cruzi-infected BALB/c mice with antibodies recognizing CXCL10/IP-10 or CCL5/RANTES during the acute phase did not alter parasitaemia, heart parasitism or inflammation. However, anti-CXCL9/Mig (monokine induced by IFN- $\gamma$ ) associated with anti-CXCL10/IP-10 led to increased 
parasitaemia and parasitism but did not affect either myocarditis severity or the transcript levels of inflammatory cell markers (CD4, CD8, F4/80), cytokines (TNF or IFN- $\gamma$ ) and chemokines (CXCL9/MIG, CXCL10/ IP-10, or CCL5/RANTES) in the heart tissue, as compared with isotype-treated control mice (Hardison et al. 2006c). These data indicate that CXC-chemokines promote a protective immune response to parasite without contributing to cardiac inflammation.

The role played by CC-chemokines in myocarditis and cardiomyopathy development during $T$. cruzi infection has also been explored. Treatment of acutely infected mice with neutralising antibodies revealed that CCL3/MIP-1 $\alpha$ is involved in macrophage recruitment to infected tissue (Petray et al. 2002). Moreover, CCL3/ MIP-1 $\alpha$-deficient mice infected with the Brazil T. cruzi strain contrasting with wild-type mice presented normal cardiac activity, suggesting that CCL3/MIP- $1 \alpha$ plays an important role in cardiac remodelling during infection (Durand et al. 2006). Our recent data indicate that CCL3/MIP-1 $\alpha$ controls macrophage and CD8 ${ }^{+} \mathrm{T}$-cell, but not $\mathrm{CD}^{+}{ }^{+} \mathrm{T}$-cell, migration to the heart tissue, particularly during the chronic phase. In addition, CCL3/ MIP-1 $\alpha$ influences $\mathrm{CD}^{+}{ }^{+} \mathrm{CR} 5^{+} \mathrm{T}$-cell compartmentalisation, which may explain the reduced migration of these cells into the cardiac tissue. Our data also indicate that CCL3/MIP-1 $\alpha$ controls cardiac parasitism and cardiomyocyte lesion formation (Silverio et al. 2009). Meanwhile, CCL4/MIP-1 $\beta$ may prevent excessive inflammation and T. cruzi pathogenesis, as indicated by a recent study showing that immunisation of animals with a CCL4/MIP-1 $\beta$ DNA vaccine led to the production of antibodies that exacerbated cardiac inflammation and fibrosis without affecting parasitism (Roffê et al. 2006).

Elevated plasma chemokine levels have been correlated with worse disease in patients with heart failure (Filippatos \& Kardaras 2002). For example, high levels of CCL2/MCP-1, but not CCL3/MIP-1 $\alpha$, are directly correlated with heart dysfunction in CCC (Talvani et al. 2004a). Since CCC progression is probably multifactorial, involving an interplay between host genetics, the parasite, and environmental factors, characterisation of host genetic predisposition may help to identify risk factors for disease progression. For example, a study of a CCL2/MCP-1 single nucleotide polymorphism at the $-2518 \mathrm{~A} / \mathrm{G}$ position revealed that subjects with the CCL2/ MCP-1-2518AA genotype have a 4-fold greater risk of developing CCC than those without this genotype (Ramasawmy et al. 2006). Although the authors proposed that the CCL2/MCP-1 variant A, correlated with a low transcriptional level, is a genetic modifier of clinical outcome for $T$. cruzi infection, the CCL2/MCP-1 status of these patients and the participation of CCL2/MCP-1 in CCC progression remain to be clarified. CCL2/MCP-1 signals exclusively through CCR2, which also recognises CCL8/MCP-2, CCL7/MCP-3 and CCL13/MCP-4 (Viola \& Luster 2008). CCR2-deficient mice infected with the Colombian T. cruzi strain exhibit a transient increase in heart parasitism but not parasitaemia during acute infection. Neither the intensity of their cardiac inflammation nor their IFN- $\gamma$ and inducible nitric oxide synthase mRNA levels differs from those of wild-type mice (Hardison et al. 2006a). Conversely, CCL2 ${ }^{-/}$mice infected with the $\mathrm{Y}$ strain of $T$. cruzi are more susceptible to infection, presenting higher parasitaemia and parasitism.

In CCL2/MCP-1-deficient mice, macrophages display reduced trypanocidal activity and CCL2/MCP-1 has been shown to be important for macrophage and $\mathrm{CD} 8^{+} \mathrm{T}$-cell activation, cell migration to the cardiac tissue and inflammatory cell retention in focal infiltrates (CN Paiva et al., unpublished observations). Myocarditis intensity in acutely and chronically Colombian straininfected $\mathrm{C} 3 \mathrm{H} / \mathrm{He}$ mice is thus directly correlated with the cardiac concentration of the CC-chemokine CCL2/ MCP-1 (our unpublished observations). Together, these data indicate that the effects of CC-chemokines on the differential migration of distinct cell populations into the cardiac tissue and effector activity of the infiltrating inflammatory cells during $T$. cruzi infection should be further explored.

Chemokine receptor binding leads to integrin activation, encouraging firm leukocyte adhesion to the activated endothelium and extravasation into the inflamed tissues (Viola \& Luster 2008). Thus, characterisation of chemokine receptor expression on circulating leukocytes may foster better comprehension of the roles of different cell populations in tissue injury. Peripheral blood mononuclear cells (PBMCs) of chagasic patients tend to express CCR5 and CXCR4 at a higher frequency than those of non-infected individuals (Talvani et al. 2004b). A high frequency of circulating $\mathrm{CCR} 5^{+}$lymphocytes, which were mainly $\mathrm{CD} 8^{+}$, was also detected in acutely $T$. cruzi-infected mice (Marino et al. 2004). Interestingly, this increase in $\mathrm{CCR}^{+}$cells among the PBMC population occurs 14 days post-infection (Silva et al. 2007), coinciding with augmentation of LFA- $1^{\text {high }}$ VAL $4^{\text {high }}$ activated PBMC numbers and myocardium colonisation by inflammatory cells (Marino et al. 2003). Studies of CCR 5 59029A/G gene polymorphism in Peruvian (Calzada et al. 2001) and Venezuelan patients (Ferrnandez-Mestre et al. 2004) revealed that the $G$ allele, which reduces CCR5 expression, is found more frequently in asymptomatic patients than in cardiopatics. Together, these data suggest that CCR5 may be linked to CCC severity. In vitro stimulation of PBMCs from CCC patients with T. cruzi antigens also enhances the frequency of $\mathrm{CD} 4^{+}$ and $\mathrm{CD}^{+} \mathrm{T}$ lymphocytes co-expressing CCR $5 / \mathrm{IFN}-\gamma$, CXCR3/IFN- $\gamma$ and CXCR3/TNF (Gomes et al. 2005). Meanwhile, asymptomatic patients had an increased frequency of $\mathrm{CD} 4^{+} \mathrm{T}$ and $\mathrm{CD} 8^{+}$lymphocytes co-expressing CCR3/IL-10 and CCR3/IL-4. Therefore, CCC genesis may be correlated with the migration of cells bearing chemokine receptors and expressing specific effector functions from the peripheral blood to the cardiac tissue (Lannes-Vieira 2003). In the cardiac tissue of Colombian strain-infected $\mathrm{C} 3 \mathrm{H} / \mathrm{He}$ mice, there is a predominance of $\mathrm{CD}^{+} \mathrm{CCR}^{+} \mathrm{T}$ lymphocytes relative to $\mathrm{CCR}^{+} \mathrm{CD}^{+} \mathrm{T}$ cells (Marino et al. 2004). To modulate heart inflammation, mice were treated with N-terminal-methionylated RANTES (Met-RANTES), a selective partial antagonist that acts on CCR1 and CCR5. This drug did not interfere with heart parasitism but significantly reduced the 
numbers of $\mathrm{CD} 4^{+}, \mathrm{CD}^{+}$and $\mathrm{CCR} 5^{+}$lymphocytes in the tissue. Furthermore, decreased fibronectin deposition paralleled an increase in the survival of treated animals. Notably, the number of IFN- $\gamma^{+}$cells in the heart was similar in saline-injected and Met-RANTES-treated mice, while the IL- $4^{+}$cell count was drastically reduced in the treated mice (Marino et al. 2004). The cardiac tissue of the Met-RANTES-treated mice also exhibited lower TNF and higher IL-10 levels (Fig. 3), reflecting a more balanced cytokine milieu. These data strongly suggest that while $\mathrm{CCR}^{+}$cells are not crucial for parasite control, they may play an important role in the pathogenesis of chagasic cardiomyopathy. Importantly, Met-RANTES administration also demonstrated that T. cruzi-elicited acute meningoencephalitis is a CCR5/ CCR1-independent process (Silva et al. 2007), supporting CCR 5 targeting as a safe potential therapeutic strategy for modulating chagasic myocarditis.

\section{A}

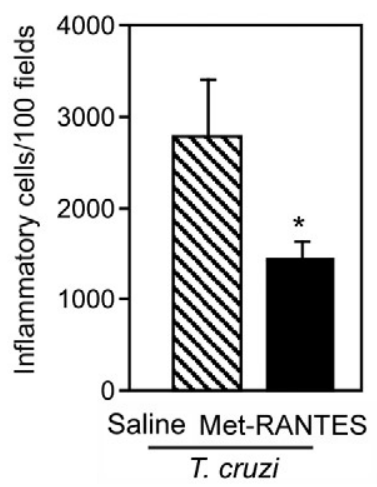

B
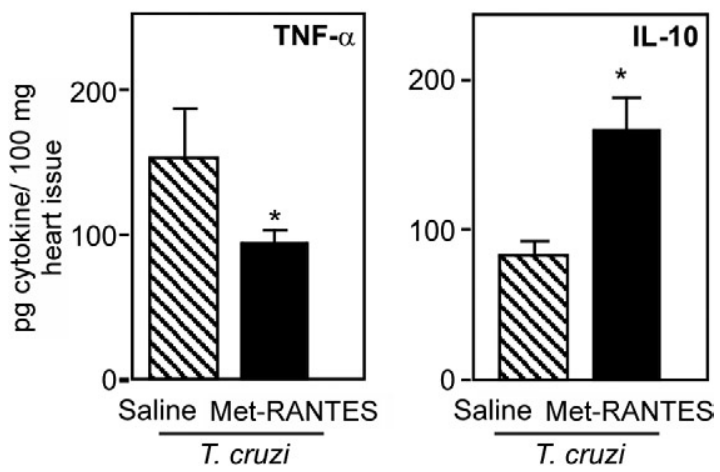

Fig. 3: total inflammatory mononuclear cells in the cardiac tissue of infected mice and concentration of the cytokines TNF and IL-10 in heart extracts of $T$. cruzi-infected $\mathrm{C} 3 \mathrm{H} / \mathrm{He}$ mice treated daily from 14-28 dpi with saline (striped bar) or methionylated- Regulation on Activation, Normal T-cell Expressed and Secreted (Met-RANTES) [black bar; $10 \mu \mathrm{g}$ of Met-RANTES/mouse as described in Marino et al. (2004)]. A: numbers of total inflammatory mononuclear cells $\left(\mathrm{CD}^{+}\right.$and $\mathrm{CD}^{+} \mathrm{T}$ cells as well as macrophages) in the cardiac tissue of infected mice treated daily with saline or Met-RANTES (Medeiros et al. 2009); B: detection of TNF and IL-10 in heart extracts of infected mice treated daily with saline or Met-RANTES (Medeiros et al. 2009). Each bar represents the mean \pm SD of experimental group composed of eight mice. The data represent two independent experiments. *: $\mathrm{p}<0.05$.
The predominance of $\mathrm{CD} 8^{+} \mathrm{CCR} 5^{+}$cells in the heart tissue of $T$. cruzi-infected animals was corroborated using C57BL/6 mice infected with the Y T. cruzi strain (Machado et al. 2005), indicating that $\mathrm{CD} 8^{+} \mathrm{CCR} 5^{+}$cell prevalence results from T. cruzi infection and is not an artefact of a particular model. Increased CCR5 expression by $\mathrm{CD} 8^{+} \mathrm{T}$ cells was detected after in vitro stimulation with a $T$. cruzi antigen (Machado et al. 2005), demonstrating the central role of the parasite in CCR5 modulation. We have also recently demonstrated that TNF signalling via TNFR1 is crucial for $\mathrm{CD} 8^{+} \mathrm{CCR} 5^{+}$ differentiation, $\mathrm{CD} 8^{+} \mathrm{CD} 44^{+} \mathrm{CD} 62 \mathrm{~L}^{\text {-low }}$ compartmentalisation and $\mathrm{CD}^{+} \mathrm{T}$ cell-enriched myocarditis formation during T. cruzi infection (Kroll-Palhares et al. 2008).

CCR5-deficient mice present an intense decrease in macrophage and T-cell migration to the heart, coupled with high parasitaemia and cardiac parasitism, especially during early infection (Hardison et al. 2006b). We recently confirmed that CCR5 is not requisite to the acute-phase survival of Colombian strain-infected mice (NF Vinagre et al., unpublished observations), supporting our proposal that CCR5 may be a rational target for immunoregulation of $T$. cruzi infection.

The intensity of chronic T. cruzi-elicited myocarditis is related to the concentrations of the CC-chemokines CCL3/MIP-1 $\alpha$ and CCL5/RANTES in the heart tissue and to the frequency of peripheral CCR $5^{+} \mathrm{LFA}-1^{+} \mathrm{T}$ lymphocytes (Medeiros et al. 2009). Given the lack of therapeutic prospects for chronic T. cruzi-elicited cardiac inflammation and our promising results using MetRANTES to treat acute infection (Marino et al. 2004), we administered this partial CCR1/CCR5 antagonist to chronically Colombian strain-infected mice. This treatment led to a $20-30 \%$ decrease in $\mathrm{CD}^{+}$cell numbers, reduced IL-10, IL-13 and TNF expression and impaired re-compartmentalisation of activated $\mathrm{CD} 4{ }^{+} \mathrm{CCR} 5^{+} \mathrm{lym}-$ phocytes. Notably, a beneficial effect of CCR1/CCR5 blockage during chronic infection was revealed by protection against connexin 43 loss in the heart tissue and creatine kinase cardiac isoenzyme MB (CK-MB) level enhancement, both of which are typically markers of heart dysfunction (Medeiros et al. 2009).

Trafficking of immunocompetent $\mathrm{CD} 8^{+} \mathrm{T}$ cells to the cardiac tissue contributes to chronic T. cruzi-elicited myocarditis in chagasic patients (Reis et al. 1993, Higuchi et al. 1997) and experimental models (dos Santos et al. 2001, Medeiros et al. 2009). There is also a correlation between $\mathrm{CD}^{+} \mathrm{T}$ cell numbers and parasite persistence in the heart tissue of chagasic patients (Reis et al. 1997). Emerging evidence suggests that $\mathrm{CD} 8^{+}$effector-cell subpopulations with varied cytotoxic and pro-inflammatory $\left(\mathrm{IFN}-\gamma^{+}\right)$abilities may determine the outcome of an inflammatory process (Sandberg et al. 2001). For instance, there is a sensible correlation between the numbers of IFN- $\gamma^{+}$and $\mathrm{TNF}^{+}$cells and $\mathrm{CD} 8^{+} \mathrm{T}$ cells and successful parasite control in CCC patients (Reis et al. 1997). In contrast, the presence of heart-infiltrating, granzyme A-expressing $\mathrm{CD} 8^{+}$cytotoxic $\mathrm{T}$ lymphocytes is associated with severe CCC (Reis et al. 1993). In this vein, our recent data showed that the number of perforin ${ }^{+}$and IFN- $\gamma^{+}$cells invading the cardiac tissue of T. cruzi-infect- 
ed mice was associated with CK-MB release and electrical abnormalities as infection progressed. Although the perforin-dependent pathway played a role in anti-T. cruzi immunity and acute-phase survival, it was not essential when mice were infected with a low inoculum of the Colombian strain. Moreover, perforin deficiency resulted in lower CK-MB isoenzyme activity in the serum and restricted connexin 43 loss, both markers of cardiac lesions and hampered the development of electrical abnormalities. The numbers of IFN- $\gamma$-producing cells were also enhanced in perforin-deficient animals, suggesting that this cell population may play a protective role in $T$. cruziinduced cardiomyopathy (Silverio et al. 2009).

The data discussed above support the idea that an appropriately intense and focussed immune response can control T. cruzi dissemination in the absence of disease, as observed in patients presenting an indeterminate form of Chagas disease. Hence, a thorough understanding of the biological forces governing leukocyte trafficking to $T$. cruzi-infected heart tissue, such as cytotoxic or inflammatory $\mathrm{CD}^{+} \mathrm{T}$ cells, may facilitate the design of treatments that regulate $\mathrm{CCC}$ without hampering parasite control. Currently, therapies using antibodies to and antagonists of CAM and chemokine receptors are being developed to selectively curb chronic inflammation in degenerative diseases (Kummer \& Ginsberg 2006, Ley et al. 2007, Viola \& Luster 2008, Horuk 2009). Therefore, the application of these strategies in parasite-triggered chronic inflammation, such as Chagas disease, to regain homeostatic balance in parasite-host interactions is an increasingly rational, attractive and realistic possibility.

\section{ACKNOWLEDGMENTS}

To Dr. Ricardo Lourenço (Editor of the Memórias do Instituto Oswaldo Cruz), for authorizing the reproduction of the original drawing made by Castro Silva (Chagas 1919), reproduced in Fig. 1.

\section{REFERENCES}

Abram CL, Lowell CA 2009. The ins and outs of leukocyte integrin signaling. Annu Rev Immunol 27: 339-362.

Aliberti JC, Machado FS, Souto JT, Campanelli AP, Teixeira MM, Gazzinelli RT, Silva JS 1999. beta-chemokines enhance parasite uptake and promote nitric oxide-dependent microbiostatic activity in murine inflammatory macrophages infected with Trypanosoma cruzi. Infect Immun 67: 4819-4826.

Aliberti JC, Souto JT, Marino AP, Lannes-Vieira J, Teixeira MM, Farber J, Gazzinelli RT, Silva JS 2001. Modulation of chemokine production and inflammatory responses in interferon-gammaand tumor necrosis factor-R1-deficient mice during Trypanosoma cruzi infection. Am J Pathol 158: 1433-1440.

Benvenuti LA, Higuchi ML, Reis MM 2000. Upregulation of adhesion molecules and class I HLA in the myocardium of chronic chagasic cardiomyopathy and heart allograft rejection, but not in dilated cardiomyopathy. Cardiovasc Pathol 9: 111-117.

Bromley SK, Mempel TR, Luster AD 2008. Orchestrating the orchestrators: chemokines in control of T cell traffic. Nat Immunol 9: 970-980.

Butcher EC 1991. Leukocyte-endothelial cell recognition: three (or more) steps to specificity and diversity. Cell 67: 1033-1036.
Calzada JE, Nieto A, Beraún Y, Martín J 2001. Chemokine receptor CCR5 polymorphisms and Chagas' disease cardiomyopathy. Tissue Antigens 58: 154-158.

Carvalho CM, Andrade MC, Xavier SS, Mangia RH, Britto CC, Jansen AM, Fernandes O, Lannes-Vieira J, Bonecini-Almeida MG 2003. Chronic Chagas' disease in rhesus monkeys (Macaca mulatta): evaluation of parasitemia, serology, electrocardiography, echocardiography, and radiology. Am J Trop Med Hyg 68: 683-691.

Chagas C 1909. Nova tripanosomiase humana. Estudos sobre a morfolojia e o ciclo evolutivo do Schizotrypanum cruzi n.g., n.sp., ajente etiolojico de nova entidade morbida do homem. Mem Inst Oswaldo Cruz 1: 159-218.

Chagas C 1911. Nova entidade morbida do homem: rezumo geral de estudos etiolojicos e clinicos. Mem Inst Oswaldo Cruz 3: 219-275.

Chagas C 1916. Processos patojenicos da tripanozomiase americana. Mem Inst Oswaldo Cruz 8: 5-35.

Chagas C, Villela E 1922. Cardiac form of American trypanosomiasis. Mem Inst Oswaldo Cruz 14: 3-54.

Coura JR 2007. Chagas disease: what is known and what is needed - a background article. Mem Inst Oswaldo Cruz 102: 113-122.

D'avila Reis D, Jones EM, Tostes Jr S, Lopes ER, Gazzinelli G, Colley DG, Mc Curley TL 1993. Characterization of inflammatory infiltrates in chronic chagasic myocardial lesions: presence of tumor necrosis factor- $\alpha+$ cells and dominance of granzyme $\mathrm{A}^{+}, \mathrm{CD}^{+}$ lymphocytes. Am J Trop Med Hyg 48: 637-644.

Dias JC 2007. Southern Cone Initiative for the elimination of domestic populations of Triatoma infestans and the interruption of transfusional Chagas disease. Historical aspects, present situation and perspectives. Mem Inst Oswaldo Cruz 102: 11-18.

dos Santos PV, Roffê E, Santiago HC, Torres RA, Marino AP, Paiva CN, Silva AA, Gazzinelli RT, Lannes-Vieira J 2001. Prevalence of CD8 $\left({ }^{+}\right)$alpha beta $\mathrm{T}$ cells in Trypanosoma cruzi-elicited myocarditis is associated with acquisition of CD62L $\left({ }^{\mathrm{Low}}\right) \mathrm{LFA}-1\left({ }^{\mathrm{High}}\right)$ VLA-4 $\left({ }^{\mathrm{High}}\right)$ activation phenotype and expression of IFN-gammainducible adhesion and chemoattractant molecules. Microbes Infect 3: 971-984.

Durand JL, Tang B, Gutstein DE, Petkova S, Teixeira MM, Tanowitz HB, Jelicks LA 2006. Dyskinesis in chagasic myocardium: centerline analysis of wall motion using cardiac-gated magnetic resonance images of mice. Magn Reson Imaging 24: 1051-1057.

Fernández-Mestre MT, Montagnani S, Layrisse Z 2004. Is the CCR559029-G/G genotype a protective factor for cardiomyopathy in Chagas disease? Hum Immunol 65: 725-728.

Filippatos GS, Kardaras F 2002. Chemokines and other novel inflammatory markers in hypertension: what can their plasma levels tell us? Int J Cardiol 83: 21-23.

Gomes JA, Bahia-Oliveira LM, Rocha MO, Busek SC, Teixeira MM, Silva JS, Correa-Oliveira R 2005. Type 1 chemokine receptor expression in Chagas' disease correlates with morbidity in cardiac patients. Infect Immun 73: 7960-7966.

Hardison JL, Kuziel WA, Manning JE, Lane TE 2006a. Chemokine $\mathrm{CC}$ receptor 2 is important for acute control of cardiac parasitism but does not contribute to cardiac inflammation after infection with Trypanosoma cruzi. J Infect Dis 193: 1584-1588.

Hardison JL, Wrightsman RA, Carpenter PM, Kuziel WA, Lane TE, Manning JE 2006b. The CC chemokine receptor 5 is important in control of parasite replication and acute cardiac inflammation following infection with Trypanosoma cruzi. Infect Immun 74: 135-143.

Hardison JL, Wrightsman RA, Carpenter PM, Lane TE, Manning JE 
2006c.The chemokines CXCL9 and CXCL10 promote a protective immune response but do not contribute to cardiac inflammation following infection with Trypanosoma cruzi. Infect Immun 74: $125-134$.

Higuchi MD, Ries MM, Aiello VD, Benvenuti LA, Gutierrez PS, Bellotti G, Pileggi F 1997. Association of an increase in CD8 ${ }^{+} \mathrm{T}$ cells with the presence of Trypanosoma cruzi antigens in chronic, human, chagasic myocarditis. Am J Trop Med Hyg 56: 485-489.

Higuchi M de L, Benvenuti LA, Martins Reis M, Metzger M 2003. Pathophysiology of the heart in Chagas' disease: current status and new developments. Cardiovasc Res 60: 96-107.

Higuchi M de L, Gutierrez PS, Aiello VD, Palomino S, Bocchi E, Kalil J, Bellotti G, Pileggi F 1993. Immunohistochemical characterization of infiltrating cells in human chronic chagasic myocarditis: comparison with myocardial rejection process. Virchows Arch A Pathol Anat Histopathol 423: 157-160.

Horuk R 2009. Chemokine receptor antagonists: overcoming developmental hurdles. Nat Rev Drug Discov 8: 23-33.

Huang H, Calderon TM, Berman JW, Braunstein VL, Weiss LM, Wittner M, Tanowitz HB 1999. Infection of endothelial cells with Trypanosoma cruzi activates NF-kappaB and induces vascular adhesion molecule expression. Infect Immun 67: 5434-5440.

Jones EM, Colley DG, Tostes S, Lopes ER, Vnencak-Jones CL, McCurley TL 1993. Amplification of a Trypanosoma cruzi DNA sequence from inflammatory lesions in human chagasic cardiomyopathy. Am J Trop Med Hyg 48: 348-357.

Kierszenbaum F 1985. Is there autoimmunity in Chagas disease? Parasitol Today 1: 4-6.

Kierszenbaum F 2005. Where do we stand on the autoimmunity hypothesis of Chagas disease? Trends Parasitol 21: 513-516.

Kroll-Palhares K, Silverio JC, Silva AA, Michailowsky V, Marino AP, Silva NM, Carvalho CM, Pinto LM, Gazzinelli RT, LannesVieira J 2008. TNF/TNFR1 signaling up-regulates CCR5 expression by $\mathrm{CD} 8^{+} \mathrm{T}$ lymphocytes and promotes heart tissue damage during Trypanosoma cruzi infection: beneficial effects of TNFalpha blockade. Mem Inst Oswaldo Cruz 103: 375-385

Kummer C, Ginsberg MH 2006. New approaches to blockade of alpha4-integrins, proven therapeutic targets in chronic inflammation. Biochem Pharmacol 72: 1460-1468.

Lannes-Vieira J 2003. Trypanosoma cruzi-elicited CD8 ${ }^{+} \mathrm{T}$ cell-mediated myocarditis: chemokine receptors and adhesion molecules as potential therapeutic targets to control chronic inflammation? Mem Inst Oswaldo Cruz 98: 299-304.

Laranja FS, Dias E, Nobrega GC, Miranda A 1956. Chagas' disease. A clinical, epidemiologic and pathologic study. Circulation 14: 1035-1060.

Laranja FS, Dias E, Pellegrino J 1950. Chagas' heart disease: a cardiological entity, Resumes de Ier Congress Mondial de Cardiologie, Paris, p. 302.

Laucella S, De Titto EH, Segura EL, Orn A, Rottenberg ME 1996a. Soluble cell adhesion molecules in human Chagas' disease: association with disease severity and stage of infection. Am J Trop Med Hyg 55: 629-634.

Laucella S, Salcedo R, Castaños-Velez E, Riarte A, De Titto EH, Patarroyo M, Orn A, Rottenberg ME 1996b. Increased expression and secretion of ICAM-1 during experimental infection with Trypanosoma cruzi. Parasite Immunol 18: 227-239.

Laucella SA, Segura EL, Riarte A, Sosa ES 1999. Soluble platelet selectin (sP-selectin) and soluble vascular cell adhesion molecule-1 (sVCAM-1) decrease during therapy with benznidazole in chil- dren with indeterminate form of Chagas' disease. Clin Exp Immunol 118: 423-427.

Ley K, Laudanna C, Cybulsky MI, Nourshargh S 2007. Getting to the site of inflammation: the leukocyte adhesion cascade updated. Nat Rev Immunol 7: 678-689.

Lima MF, Zhang Y, Villalta F 1997. Beta-chemokines that inhibit HIV-1 infection of human macrophages stimulate uptake and promote destruction of Trypanosoma cruzi by human macrophages. Cell Mol Biol 43: 1067-1076.

Luo BH, Carman CV, Springer TA 2007. Structural basis of integrin regulation and signaling. Annu Rev Immunol 25: 619-647.

Machado FS, Koyama NS, Carregaro V, Ferreira BR, Milanezi CM, Teixeira MM, Rossi MA, Silva JS 2005. CCR5 plays a critical role in the development of myocarditis and host protection in mice infected with Trypanosoma cruzi. J Infect Dis 191: 627-636.

Machado FS, Martins GA, Aliberti JC, Mestriner FL, Cunha FQ, Silva JS 2000. Trypanosoma cruzi-infected cardiomyocytes produce chemokines and cytokines that trigger potent nitric oxidedependent trypanocidal activity. Circulation 102: 3003-3008.

Marin-Neto JA, Rassi A Jr, Morillo CA, Avezum A, Connolly SJ, Sosa-Estani S, Rosas F, Yusuf S 2008. BENEFIT Investigators Rationale and design of a randomized placebo-controlled trial assessing the effects of etiologic treatment in Chagas' cardiomyopathy: the BENznidazole Evaluation for Interrupting Trypanosomiasis (BENEFIT). Am Heart $J$ 156: 37-43.

Marino AP, Azevedo MI, Lannes-Vieira J 2003. Differential expression of adhesion molecules shaping the T-cell subset prevalence during the early phase of autoimmune and Trypanosoma cruzielicited myocarditis. Mem Inst Oswaldo Cruz 98: 945-952.

Marino AP, da Silva A, dos Santos P, Pinto LM, Gazzinelli RT, Teixeira MM, Lannes-Vieira J 2004. Regulated on activation, normal T cell expressed and secreted (RANTES) antagonist (MetRANTES) controls the early phase of Trypanosoma cruzi-elicited myocarditis. Circulation 110: 1443-1449.

Medeiros GA, Silvério JC, Marino AP, Roffê E, Vieira V, Kroll-Palhares K, Carvalho CE, Silva AA, Teixeira MM, Lannes-Vieira J 2009. Treatment of chronically Trypanosoma cruzi-infected mice with a CCR1/CCR5 antagonist (Met-RANTES) results in amelioration of cardiac tissue damage. Microbes Infect 11: 264-273.

Melo RC, Brener Z 1978. Tissue tropism of different Trypanosoma cruzi strains. J Parasitol 64: 475-482.

Michailowsky V, Celes MR, Marino AP, Silva AA, Vieira LQ, Rossi MA, Gazzinelli RT, Lannes-Vieira J, Silva JS 2004. Intercellular adhesion molecule 1 deficiency leads to impaired recruitment of $\mathrm{T}$ lymphocytes and enhanced host susceptibility to infection with Trypanosoma cruzi. J Immunol 173: 463-470.

Petray P, Corral R, Meckert P, Laguens R 2002. Role of macrophage inflammatory protein-1alpha (MIP-1alpha) in macrophage homing in the spleen and heart pathology during experimental infection with Trypanosoma cruzi. Acta Trop 83: 205-211.

Proudfoot AE 2002. Chemokine receptors: multifaceted therapeutic targets. Nat Rev Immunol 2: 106-115.

Ramasawmy R, Cunha-Neto E, Fae KC, Martello FG, Müller NG, Cavalcanti VL, Ianni B, Mady C, Kalil J, Goldberg AC 2006. The monocyte chemoattractant protein-1 gene polymorphism is associated with cardiomyopathy in human chagas disease. Clin Infect Dis 43: 305-311.

Reis DD, Jones EM, Tostes S Jr, Lopes ER, Gazzinelli G, Colley DG, McCurley TL 1993. Characterization of inflammatory infiltrates in chronic chagasic myocardial lesions: presence of tumor necrosis factor-alpha ${ }^{+}$cells and dominance of granzyme $\mathrm{A}^{+}, \mathrm{CD} 8^{+}$lymphocytes. Am J Trop Med Hyg 48: 637-644. 
Reis MM, Higuchi Mde L, Benvenuti LA, Aiello VD, Gutierrez PS, Bellotti G, Pileggi F 1997. An in situ quantitative immunohistochemical study of cytokines and IL-2 $\mathrm{R}^{+}$in chronic human chagasic myocarditis: correlation with the presence of myocardial Trypanosoma cruzi antigens. Clin Immunol Immunopathol 83: 165-172.

Ribeiro Dos Santos R, Hudson L 1980. Trypanosoma cruzi: immunological consequences of parasite modification of host cells. Clin Exp Immunol 40: 36-41.

Roffê E, Silva AA, Marino AP, dos Santos PV, Lannes-Vieira J 2003. Essential role of VLA-4/VCAM-1 pathway in the establishment of $\mathrm{CD}^{+} \mathrm{T}$-cell-mediated Trypanosoma cruzi-elicited meningoencephalitis. J Neuroimmunol 142: 17-30.

Roffê E, Souza AL, Caetano BC, Machado PP, Barcelos LS, Russo RC, Santiago HC, Souza DG, Pinho V, Tanowitz HB, Camargos ER, Bruña-Romero O, Teixeira MM 2006. A DNA vaccine encoding CCL4/MIP-1beta enhances myocarditis in experimental Trypanosoma cruzi infection in rats. Microbes Infect 8: 27452755.

Sandberg JK, Fast NM, Nixon DF 2001. Functional heterogeneity of cytokines and cytolytic effector molecules in human CD8 $8^{+} \mathrm{T}$ lymphocytes. J Immunol 167: 181-187.

Santos-Buch CA, Teixeira AR 1974. The immunology of experimental Chagas' disease. 3. Rejection of allogeneic heart cells in vitro. J Exp Med 140: 38-53.

Schmunis GA 2007. Epidemiology of Chagas disease in non-endemic countries: the role of international migration. Mem Inst Oswaldo Cruz 102: 75-85.

Sigmundsdottir H, Butcher EC 2008. Environmental cues, dendritic cells and the programming of tissue-selective lymphocyte trafficking. Nat Immunol 9: 981-987.

Silva AA, Roffê E, Santiago H, Marino AP, Kroll-Palhares K, Teixeira MM, Gazzinelli RT, Lannes-Vieira J 2007. Trypanosoma cru$z i$-triggered meningoencephalitis is a CCR1/CCR5-independent inflammatory process. J Neuroimmunol 184: 156-163.

Silverio JC, Pinto LMO, Silva AA, Oliveira GO, Lannes-Vieira J 2009. Perforin-expressing cytotoxic cells contribute to chronic cardiomyopathy in Trypanosoma cruzi infection. Int $J$ Exp Pathol, in press.
Soares MBP, Ribeiro dos Santos R 2009. Current status and perspectives of cell therapy in Chagas disease. Mem Inst Oswaldo Cruz 104(Suppl. I): 325-332.

Soeiro MN, de Castro SL 2009. Trypanosoma cruzi targets for new chemotherapeutic approaches. Expert Opin Ther Targets 13: 105-121.

Springer TA 1995. Traffic signals on endothelium for lymphocyte recirculation and leukocyte emigration. Annu Rev Physiol 57: $827-872$

Talvani A, Ribeiro CS, Aliberti JC, Michailowsky V, Santos PV, Murta SM, Romanha AJ, Almeida IC, Farber J, Lannes-Vieira J, Silva JS, Gazzinelli RT 2000. Kinetics of cytokine gene expression in experimental chagasic cardiomyopathy: tissue parasitism and endogenous IFN-gamma as important determinants of chemokine mRNA expression during infection with Trypanosoma cruzi. Microbes Infect 2: 851-866.

Talvani A, Rocha MO, Barcelos LS, Gomes YM, Ribeiro AL, Teixeira MM 2004a. Elevated concentrations of CCL2 and tumor necrosis factor-alpha in chagasic cardiomyopathy. Clin Infect Dis 38: $943-950$

Talvani A, Rocha MO, Ribeiro AL, Correa-Oliveira R, Teixeira MM 2004b. Chemokine receptor expression on the surface of peripheral blood mononuclear cells in Chagas disease. J Infect Dis 189: 214-220.

Tarleton RL, Zhang L, Downs MO 1997. "Autoimmune rejection” of neonatal heart transplants in experimental Chagas disease is a parasite-specific response to infected host tissue. Proc Natl Acad Sci USA 94: 3932-3937.

Villalta F, Zhang Y, Bibb KE, Kappes JC, Lima MF 1998. The cysteine-cysteine family of chemokines RANTES, MIP-1alpha and MIP-lbeta induce trypanocidal activity in human macrophages via nitric oxide. Infect Immun 66: 4690-4695.

Viola A, Luster AD 2008. Chemokines and their receptors: drug targets in immunity and inflammation. Annu Rev Pharmacol Toxicol 48: 171-197.

Yamauchi LM, Aliberti JC, Baruffi MD, Portela RW, Rossi MA, Gazzinelli RT, Mineo JR, Silva JS 2006. The binding of CCL2 to the surface of Trypanosoma cruzi induces chemo-attraction and morphogenesis. Microbes Infect 9: 111-118. 